\title{
Gerenciamento de Resultados: Investigação de sua Ocorrência em Empresas de Setores Regulados no Brasil
}

\author{
Earnings Management: investigation of their occurrence in Companies \\ Regulated Sectors in Brazil
}

\author{
Alexandre Corrêa dos Santos \\ alexandre@viawork.com.br \\ FURB \\ Vinícius Costa da Silva Zonatto \\ viniciuszonatto@gmail.com
} FURB

\author{
Idair Edson Marcello \\ idairmarcello@al.furb.br \\ FURB
}

Jorge Ribeiro de Toledo Filho jtoledo@furb.br

FURB

\section{Resumo}

Este estudo tem por objetivo investigar se empresas listadas na BM\&FBovespa, pertencentes a setores regulados efetuam gerenciamento de resultados contábeis (GR), e identificar se a relação entre o índice de governança corporativa dessas empresas influencia no nível de gerenciamento dos resultados das mesmas. A pesquisa caracteriza-se como Descritiva em relação a seu objetivo; Documental quanto aos procedimentos e Quantitativa quanto a sua abordagem. Os dados analisados foram coletados junto ao software Economática ${ }^{\circledR}$ para o período de 2005 a 2009. Para a análise dos dados utilizou-se o modelo KS para o cálculo do gerenciamento de resultados. As medidas representativas do índice de governança corporativa das organizações representam as variáveis dependentes da pesquisa. Para verificar a relação entre gerenciamento de resultados e o índice de governança corporativa destas empresas, foi realizado o teste-T de diferenças de médias. Os resultados encontrados sugerem $\mathrm{o}$ gerenciamento de resultados nas companhias de setores regulados. No entanto, não foram encontradas diferenças estatisticamente significativas entre o nível de gerenciamento de resultado de empresas dos setores regulados com governança corporativa e companhias sem esta característica.

Palavras-chave: Gerenciamento de Resultados; Accruals; Setores Regulados.

\begin{abstract}
This study aims to investigate whether companies listed on BM\&FBovespa, belonging to regulated industries, perform accounting earnings management, and to identify if the relationship between the corporate governance index of these companies influences the level theirs earning management. The research is characterized as Descriptive in relation to your goal; Documentary in relation to procedures and Quantitative toward Approach. The data analyzed were collected from Economática ${ }^{\circledR}$ Software for the period 2005 to 2009. To analyze the data was used the KS model to calculate the discretionary accrual. The representative measures to the corporate governance index representing the dependent variable. To investigate the relationship between earnings management and corporate governance index of these companies, was used T-test for the differences between means. The results suggest earnings management on the companies in regulated sectors. However, no statistically significant differences were found between the level of earnings management of companies in regulated sectors and companies with corporate governance without this feature.
\end{abstract}

Keywords: Earnings Management, Accruals, Regulated Industries.

Artigo recebido em: 13.05.2012; Aceito em: 12.11.2012

R. Cont. Ufba, Salvador-Ba, v. 6, n. 3, p. 04-16, setembro-dezembro 2012 


\section{INTRODUÇÃO}

A contabilidade pode ser entendida como um centro processador de informações, de natureza econômica e financeira, que auxilia os gestores no processo de tomada de decisão. De acordo com Iudícibus, Martins e Gelbcke (2000, p. 42), "a contabilidade é, objetivamente, um sistema de informação e avaliação destinado a prover seus usuários com demonstrações e análises de natureza econômica, financeira, física e de produtividade, com relação à entidade objeto de contabilização".

Em razão das demonstrações contábeis das organizações de capital aberto submeterem-se obrigatoriamente à auditoria, pressupõe-se que, apresentem, de forma fidedigna o real desempenho das organizações. Contudo, observa-se de uma forma geral, que as organizações vivenciam atualmente um ambiente de crescente regulação. Resquícios de um passado econômico instável, faz com que os órgãos reguladores vigiem a atuação das organizações para evitar desequilíbrios cambiais, comerciais e o retorno da inflação.

Neste contexto, normas políticas, tributárias e/ou ambientais, são criadas para que essas organizações atendam os interesses sociais coletivos, sem, contudo, deixar de gerar riquezas e crescimento econômico.

No Brasil, alguns setores privados tem direta intervenção do governo federal. São os chamados Setores Regulados, cuja atuação está sob a égide da regulamentação pública dos governos. A prestação de contas accountability dessas organizações também sofre influência de normas públicas, por este motivo espera-se que suas demonstrações contábeis não sofram o efeito do Gerenciamento de Resultados, ou seja, que seus resultados reflitam sua real situação econômico-financeira, sem o efeito dos atos discricionários de seus gestores.

O gerenciamento de resultados contábeis ou earnings management pode ser entendido como a "alteração proposital (intencional) dos resultados contábeis dentro dos limites legais, dadas à discricionariedade e à flexibilidade permitidas pelas normas e práticas contábeis, visando ao alcance de motivação particular". (MARTINEZ, 2001, p. 12).

Alguns estudos encontraram evidências de que algumas organizações manipulam seus accruals na contabilidade para gerenciarem seus ganhos (JONES, 1991; CAHAN, 1992; HAN e WANG, 1998; MARTINEZ; 2001; COSENZA e GRATERON, 2003; SANCOVSCHI e MATOS, 2003; GOULART, 2004; CUPERTINO, 2004a, 2004b; MARTINEZ; 2001 e LOPES e TUKAMOTO, 2007).

Neste contexto a questão que norteia a pesquisa é: Empresas listadas na BM\&FBovespa, pertencentes a setores regulados, gerenciam seus resultados contábeis?

Em se confirmando este pressuposto de pesquisa, qual a influência do índice de Governança Corporativa dessas empresas no Gerenciamento de Resultados?

Este estudo tem por objetivo investigar se empresas listadas na BM\&FBovespa, pertencentes a setores regulados efetuam gerenciamento de resultados contábeis (GR), e identificar se a relação entre o índice de governança corporativa dessas empresas influencia no nível de gerenciamento dos resultados das mesmas.

A pesquisa foi estruturada em cinco seções, a saber: introdução; fundamentação teórica, subdividida em temas que tratam do gerenciamento de resultados, setores regulados no Brasil e governança corporativa; aspectos metodológicos; análise dos resultados e considerações finais. 


\section{REFERENCIAL TEÓRICO}

Nesta seção do trabalho serão apresentadas as temáticas que comporão o marco teórico da pesquisa. Inicialmente será realizada uma contextualização sobre o gerenciamento de resultados e serão apresentados alguns estudos que abordam o tema, em seguida será realizada uma explanação sobre os setores regulados no Brasil e por fim a temática governança corporativa será abordada, buscando-se encontrar evidencias de sua influência no GR de empresas de setores regulados.

\subsection{Gerenciamento de Resultados}

O GR tem sido alvo de muitas pesquisas no meio científico internacional. No Brasil, Cardoso (2005) afirma que os estudos ainda são incipientes e cita os estudos de Martinez (2001; 2004); Cosenza e Grateron (2003); Sancovschi e Matos (2003); Goulart (2004); Cupertino (2004a; 2004b) e Tukamoto (2007), como importantes.

Healy e Wahlen (1999), explicam que o gerenciamento de resultados ocorre quando os gestores usam do julgamento na elaboração dos relatórios financeiros e na estruturação das transações com o intuito de alterar os relatórios financeiros e não chamar ou chamar atenção de alguns stakeholders sobre o desempenho econômico-financeiro da empresa ou para influenciar os resultados de eventuais contratos que dependem dos números contábeis divulgados.

Grateron (2003) afirma que qualquer distorção na conformação correta da informação deve ser entendida como uma espécie de fraude.

Neste trabalho é adotado o entendimento de Martinez (2001), de que o GR não é fraude contábil, ou seja, as ações do gestor operam dentro dos limites do que prescreve a legislação contábil nos pontos que em que as normas contábeis facultam certa discricionariedade.

Nesta linha de consideração, Dechow e Skinner (2000) realizam uma separação entre GR e fraude, explicam que o GR é praticado em consonância aos princípios contábeis geralmente aceitos, enquanto a fraude é realizada à revelia das mesmas.

Quando o tema remete a setores regulados, espera-se, que em empresas desses setores não ocorra o GR devido as fortes restrições regulatórias que as cercam, contudo, o resultado do estudo de Bowman e Navissi (2003), que investigou a associação entre retornos anormais e GR no contexto da regulamentação de preços, mostra que os regulamentos de controle de preço afetam os preços das empresas da amostra negativamente, assim, empresas fazem os rendimentos diminuírem discricionariamente para aumentar a probabilidade de aprovação do aumento de preços e empresas que são mais afetadas negativamente pelos regulamentos gerem os seus resultados de forma mais agressiva.

$\mathrm{O}$ ambiente legal influencia o GR, ou seja, as empresas de setores regulados podem ser estimuladas a praticar o gerenciamento, como consequência de legislação que a afete, e se a prática a beneficiar (BAPTISTA, 2008), em consequência, pode trazer consequências negativas aos interesses políticos e sociais, como por exemplo, o prejuízo à redução de tarifas (COSENZA, 2003).

Silva, Galdi e Teixeira (2010) investigaram o efeito da regulação econômica e das eleições presidenciais no gerenciamento de resultados das companhias no mercado de capitais brasileiro. Este estudo considerou empresas atuantes em setores regulados pelo Governo Federal, e utilizou o modelo de Han e Wang (1998). O resultado deste trabalho mostrou que há indícios de que empresas brasileiras com ações listadas na BM\&FBovespa atuantes em setores regulados, após a criação das agências reguladoras, utilizam os acrruals para gerenciarem seus resultados contábeis. 


\subsection{Setores Regulados no Brasil}

Os setores de serviços de infraestrutura, chamados public utilities fazem parte do denominado monopólio natural. No Brasil, a razão para que os serviços de água, energia elétrica e comunicações se constituam monopólio natural deve-se à presença de grandes economias de escala (quanto maior a quantidade produzida, menor o custo de produção) e de escopo (a produção conjunta de dois bens é mais barata do que se realizada em separado), em que, uma vez ocorrendo grandes investimentos na construção de uma rede principal, a ligação de um consumidor local tem um custo marginal bastante baixo (PEANO, 2005).

Esses serviços requerem um alto investimento de capital para a sua operacionalização. $\mathrm{O}$ resultado é a existência de uma única ou poucas empresas explorando estas atividades. A regulação econômica surge para maximizar estas economias para que não haja falta dos serviços aos consumidores e que os valores também não sejam abusivos em relação a outros serviços praticados.

Fiani (1998, p. 1) define a regulação econômica como sendo "a ação do estado em limitar o grau de liberdade que os agentes econômicos possuem no seu processo de tomada de decisão." A função da regulação econômica é, assim, a de promover o interesse público garantindo de um lado a lucratividade que viabilize os investimentos privados e, de outro, o bem-estar dos consumidores por meio da disponibilidade do serviço, em condições adequadas de qualidade e preço. Salgado e Motta (2005, p. 6) informam que "o grande desafio do regulador é encontrar o ponto ótimo que equilibre rentabilidade da operação e bem-estar".

Uma dificuldade que se pode levantar reside no fato das empresas privadas poderem monopolizar a prestação desses serviços e obterem com isso lucros exorbitantes. As soluções geralmente encontradas para este problema são o controle dessas atividades por meio do setor público (monopólio estatal) ou permitir que uma empresa privada detenha este monopólio mediante a concessão estatal (monopólio regulado), com o objetivo de restringir a obtenção de grandes lucros, evitando-se assim o abuso nos preços cobrados.

Neste sentido, Possas; Fagundes e Pondé (2002) afirmam que os serviços têm seus valores regulados por dois fatores: pela nacionalização das empresas atuantes nesses setores ou pela criação de órgãos reguladores. $\mathrm{O}$ objetivo governamental nesse sentido é o de proteger o consumidor do abuso de poder de mercado que pode ser imposto pelas empresas que fornecem estes serviços. O interesse público está presente visto que os bens da vida em questão representam serviços necessários para a população e que merecem, por isso, controle de suas operações.

Pires e Piccinini (1999), ao retratarem a necessidade da regulação dos serviços pelos órgãos públicos, trazem em linhas gerais os objetivos da missão regulatória, sendo eles: (i) buscar a eficiência econômica, garantindo o serviço ao menor custo para o usuário; (ii) evitar o abuso do poder de monopólio, assegurando a menor diferença entre preços e custos, de forma compatível com os níveis desejados de qualidade do serviço; (iii) assegurar o serviço universal; (iv) assegurar a qualidade do serviço prestado; (v) estabelecer canais para atender a reclamações dos usuários ou consumidores sobre a prestação dos serviços; (vi) estimular a inovação (identificar oportunidades de novos serviços, remover obstáculos e promover políticas de incentivo à inovação); (vii) assegurar a padronização tecnológica e a compatibilidade entre equipamentos; e (viii) garantir a segurança e proteger o meio ambiente. As regulações bem como as privatizações dos serviços tidos como monopólio natural tiveram início nos anos 90. Barroso (2005) comenta que essas regulações surgem num momento de reforma econômica e foi a chamada flexibilização dos monopólios estatais, culminando na implantação das Agências Reguladoras. $\mathrm{O}$ autor explica que mudanças trazidas por Emendas 
à Constituição Federal de 1988 permitiram o surgimento de órgãos estatais com funções reguladoras.

Estas agências têm como objetivo fiscalizar a prestação de serviços públicos praticados pela iniciativa privada. Além disso, elas controlam a qualidade na prestação do serviço e estabelecem regras para o setor. Segundo dados do sítio da Presidência da República Federativa do Brasil (2011), atualmente são dez o número de agências reguladoras em vigor no país, a saber:

- ANATEL (Agência Nacional de Telecomunicações) instituída em 1997.

- ANEEL (Agência Nacional de Energia Elétrica) instituída em 1996.

- ANP (Agência Nacional do Petróleo) instituída em 1998.

- ANVISA (Agência nacional de Vigilância Sanitária) instituída em 1999.

- ANS (Agência Nacional de Saúde Suplementar) instituída em 2000.

- ANA (Agência Nacional das Águas) instituída em 2000.

- ANTAQ (Agência Nacional de Transportes Aquaviários) instituída em 2001.

- ANTT (Agência Nacional de Transportes Terrestres) instituída em 2001.

- ANCINE (Agência Nacional do Cinema) instituída em 2001.

- ANAC (Agência Nacional de Aviação Civil) instituída em 2006.

As privatizações ocorridas nos anos 90 objetivaram aumentar a demanda pelos serviços públicos. Como observam Salgado e Motta (2005, p. 15) "em todos os setores a reforma regulatória procurou alcançar os mesmos objetivos: atrair investimentos, incentivando a operação eficiente e a expansão de capacidade".

\subsection{Governança Corporativa}

Segundo Sá (2003, p.120) a expressão estrutura de governança surgiu em meados de 1970 para classificar as transações econômicas pelos hábitos das instituições. Já "na década de 80, o conceito de governança corporativa foi incorporado ao direito corporativo americano para exprimir a ideia do processo institucional que conduzisse o acesso dos financiadores das empresas abertas ao valor da empresa e a forma de os financiadores governarem a sua geração".

Para Malacrida e Yamamoto (2006) a Governança Corporativa surge num contexto de mudanças na relação entre empresas e sociedade como um todo, fato que converge para a separação entre proprietários das companhias e seus administradores, em consequência, a gestão e o controle emergem como fatores de conflito entre acionistas, administradores e stakeholders.

Neste âmbito a governança corporativa utiliza os principais conceitos relacionados à contabilidade, tais como: transparência (disclosure), equidade, prestação de contas (accountability) e responsabilidade corporativa (sustentabilidade) para explicar e solucionar os conflitos existentes entre os interesses dos stakeholders (MALACRIDA e YAMAMOTO 2006).

Grun (2003) enfatiza que o modelo de governança corporativa brasileira remete a transparência contábil das empresas e o respeito aos acionistas minoritários.

As empresas que possuem Governança Corporativa no Brasil estão listadas na BM\&FBovespa e correspondem à companhias de capital aberto. Essas companhias são 
empresas privadas nacionais, estatais e subsidiárias de multinacionais. Mckinsey \& Company e Korn/Ferry International (2001), citados por Silveira (2002), traçam um modelo geral de governança corporativa para as empresas brasileiras listadas em bolsa, com as seguintes características:

- estrutura de propriedade com forte concentração das ações com direito a voto (ordinárias) e alto índice de emissão de ações sem direito a voto (preferenciais);

- empresas com controle familiar ou compartilhado por alguns poucos investidores alinhados por meio de acordo de acionistas para resolução das questões relevantes;

- presença de acionistas minoritários pouco ativos;

- alta sobreposição entre propriedade e gestão, com os membros do conselho representando os interesses dos acionistas controladores;

- pouca clareza na divisão dos papéis entre conselho e diretoria, principalmente nas empresas familiares;

- escassez de conselheiros profissionais no Conselho de Administração;

- remuneração dos conselheiros como fator pouco relevante;

- estrutura informal do Conselho de Administração, com ausência de comitês para tratamento de questões específicas, como auditoria ou sucessão.

Quanto aos objetivos, a Governança Corporativa tem o propósito de garantir a confiabilidade em uma determinada empresa para com os seus acionistas. Por meio de um conjunto eficiente de mecanismos, tanto de incentivos quanto de monitoramento, a Governança Corporativa busca assegurar que o comportamento dos executivos esteja sempre alinhado com os interesses dos acionistas (IBGC, 2011).

Nesse sentido, o IBGC (2011) trás as principais ferramentas utilizadas pela governança corporativa para alcançar seus objetivos, sendo elas: a participação, estado de direito, transparência, responsabilidade, orientação por consenso, igualdade e inclusividade, efetividade e eficiência e prestação de contas (accountability).

Uma boa governança corporativa traz benefícios no sentido de contribuir para o desenvolvimento econômico sustentável, com melhorias no desempenho das empresas, além de maior acesso a fontes externas de capital.

As práticas de boa governança corporativa são também incentivadas na Bolsa de Valores, Mercadorias e Futuros de São Paulo - BM\&FBovespa. Em dezembro de 2000 a instituição "lançou segmentos especiais de listagem de empresas, desenvolvidos com o objetivo de proporcionar um ambiente de negociação que estimulasse, simultaneamente, o interesse dos investidores e a valorização das companhias" (BM\&FBovespa, 2011). Foram criados níveis diferenciados de governança corporativa, para os quais as empresas listadas puderam, voluntariamente, aderir. Os segmentos especiais de listagem de empresas desenvolvido pela BM\&FBovespa foram denominados: Novo Mercado, Nível 2 de Governança Corporativa e Nível 1 de Governança Corporativa.

Esclarece o IBGC (2011) que os segmentos especiais caracterizam-se:

Nível 1 - por exigir práticas adicionais de liquidez das ações e disclosure. Nível 2 tem por obrigação práticas adicionais relativas aos direitos dos acionistas e conselho de administração. Novo Mercado, diferencia-se do Nível 2 pela exigência para emissão exclusiva de ações com direito a voto. Estes dois últimos apresentam como resultado esperado a redução das incertezas no processo de avaliação, investimento e de risco, o aumento de investidores interessados e, consequentemente, o fortalecimento do mercado acionário. 
Algumas empresas de setores regulados fazem parte desses segmentos especiais criados pela bolsa, trazendo com isto benefícios para os diversos stakeholders interessados em seus negócios. As empresas participantes destes segmentos apresentam maior grau de disclosure em suas demonstrações, revelando mais transparência e com isto podem ser mais competitivas, além de estreitarem os laços com seus acionistas. Isto faz com que os diversos interessados possam realizar análises ao terem acesso a essas informações disponibilizadas e verificar o comportamento em determinado período, além de poder projetar seu futuro.

Lanzana (2004 p. ii) esclarece que "o disclosure tem papel fundamental no funcionamento do mercado de capitais, sendo essencial para a adequada avaliação das oportunidades de investimentos pelos agentes econômicos, na medida em que reduz a assimetria informacional".

Bowen, Rajgopal e Venkatachalam (2005) afirmam que um sistema de Governança Corporativa fraco pode favorecer o gerenciamento de resultados, pois os acionistas possuem informações que podem influenciar os resultados futuros em relação ao fluxo de caixa e o retorno dos investimentos.

Ramos e Martinez (2006) investigaram se as boas práticas de governança corporativa de empresas brasileiras listadas na Bovespa minimizam o gerenciamento de resultados. Os resultados indicaram uma menor variabilidade dos accruals discricionários para as empresas listadas no Novo Mercado, Nível 1 e 2 de Governança Corporativa quando comparadas àquelas que não aderiram ao programa.

\section{ASPECTOS METODOLÓGICOS}

Esta pesquisa caracteriza-se como descritiva em relação a seu objetivo. Segundo Gil (2010) este tipo de pesquisa tem como objetivo a descrição das características de determinada população, ou ainda realizadas com a finalidade de identificar possíveis relações entre variáveis. Em relação à abordagem do problema remete à pesquisa quantitativa, que para Richardson (1989), representa a intenção de garantir a precisão dos resultados, evitar distorções de análise e interpretação, o que oferece maior margem de segurança quanto às inferências.

Quanto aos procedimentos esta pesquisa pode ser classificada como documental, que de acordo com Segundo Silva e Grigolo (2002), a pesquisa documental vale-se de materiais que ainda não receberam nenhuma análise aprofundada. Esse tipo de pesquisa visa, assim, selecionar, tratar e interpretar a informação bruta, buscando extrair dela algum sentido e e outros valores, podendo, desse modo, contribuir com a comunidade científica a fim de que outros possam voltar a desempenhar futuramente o mesmo papel.

O gerenciamento de resultados foi mensurado utilizando-se o modelo desenvolvido por Kang e Sivaramakrishnan (1995), conhecido no meio científico por modelo KS. Para a análise das variáveis do estudo será utilizado o software estatístico SPSS versão 18.0.

\subsection{Universo e amostra}

A população da pesquisa compreende empresas listadas na BM\&FBovespa pertencentes aos setores regulados. A amostra utilizada corresponde a 51 companhias de setores regulados, atuantes nas seguintes áreas: água (04), energia elétrica (30), telefonia fixa (12) e telefonia móvel (05).

\subsection{Coleta dos dados}


Os dados das companhias pertencentes à amostra foram coletados de suas demonstrações contábeis utilizando-se como fonte o software Economática, para o período de 2005 à 2009 . Os saldos das contas contábeis extraídos refere-se àqueles que fazem parte do cálculo no modelo KS e encontram-se demonstrados na análise dos resultados.

\section{ANÁLISE DOS RESULTADOS}

Buscando-se investigar se empresas listadas na BM\&FBovespa pertencentes a setores regulados efetuam gerenciamento de resultados contábeis, e identificar se a relação entre o índice de governança corporativa destas empresas influencia o gerenciamento de resultados das mesmas, calculou-se o gerenciamento de resultados por meio do modelo KS que consiste em achar os resíduos da regressão do modelo adotado. O método KS consiste na seguinte equação:

$$
\begin{gathered}
\mathrm{AT}_{\mathrm{it}}=\phi_{0}+\phi_{1}\left[\delta_{1} \mathrm{REC}_{\mathrm{it}}\right]+\phi_{2}\left[\delta_{2} \mathrm{DESP}_{\mathrm{it}}\right]+\phi_{3}\left[\delta_{3} \mathrm{~A} \cdot \mathrm{Imob}_{\mathrm{it}}\right]+\varepsilon_{\mathrm{it}} \\
\mathrm{AD}_{\mathrm{it}}=\mathrm{AT}_{\mathrm{it}}-\left[\phi_{0}+\phi_{1}\left[\delta_{1} \mathrm{REC}_{\mathrm{it}}\right]+\phi_{2}\left[\delta_{2} \mathrm{DESP}_{\mathrm{it}}\right]+\phi_{3}\left[\delta_{3} \mathrm{Almob}_{\mathrm{it}}\right]\right]=\varepsilon_{\mathrm{it}}
\end{gathered}
$$

Onde:

$\mathrm{AT}_{\mathrm{it}}=$ Accruals Totais $\left.=(\mathrm{CGL}-\text { Depreciação \& Amortização })_{\mathrm{t}}\right)$.

$\operatorname{Rec}_{i t}=$ Receita Líquida (excluindo tributação).

Desp $_{\text {it }}=$ Custos e Despesas Operacionais antes da Depreciação \& Amortização.

$\mathrm{CGL}=$ Capital de giro Líquido excluindo as disponibilidades, financiamentos de curto prazo e provisão de Impostos a Pagar.

At. Imob $_{\text {it }}=$ Ativo Imobilizado e Ativo Diferido.

C.Receber $\mathrm{i}_{\mathrm{t}-\mathrm{-}-\mathrm{l}}=$ Contas a Receber no período $\mathrm{t}-1$.

Deprec $_{\mathrm{i}, \mathrm{t}-1}=$ Despesas de Depreciação.

$\delta_{1}=$ C.Receber $\mathrm{R}_{\mathrm{i}, \mathrm{t}-1} / \operatorname{Rec}_{\mathrm{i}, \mathrm{t}-1}$, onde CR (Contas a Receber).

$\delta_{2}=\left(\Delta \mathrm{CG}-\mathrm{C} \cdot \mathrm{Rec}_{\mathrm{it}}\right) / \operatorname{Desp}_{\mathrm{i}, \mathrm{t}-1}$.

$\delta_{3}=$ Deprec $_{\mathrm{i}, \mathrm{t}-1} / \mathrm{A} \cdot \operatorname{Imob}_{\mathrm{i}, \mathrm{t}-1}$.

Os resultados foram obtidos por meio da realização de cinco regressões, cada qual para um ano específico de análise. A Tabela 1 descreve os resultados auferidos pelas regressões.

Tabela 1: Resultados da Regressão dos Modelos

\begin{tabular}{ccccccc}
\hline Modelo & $\mathrm{R}$ & $\mathrm{R}^{2}$ & $\mathrm{R}^{2}$ Ajustado & $\begin{array}{c}\text { Erro Padrão } \\
\text { Estimado }\end{array}$ & $\mathrm{F}$ & Sig. \\
\hline 2009 & 0,861 & 0,741 & 0,724 & 0,061 & 44,754 & 0,000 \\
\hline 2008 & 0,993 & 0,985 & 0,984 & 0,187 & $1.034,083$ & 0,000 \\
\hline 2007 & 0,545 & 0,297 & 0,252 & 0,287 & 6,608 & 0,001 \\
\hline 2006 & 0,504 & 0,254 & 0,207 & 0,145 & 5,339 & 0,003 \\
\hline 2005 & 0,466 & 0,217 & 0,167 & 0,098 & 4,350 & 0,009 \\
\hline
\end{tabular}

Fonte: Dados da Pesquisa

Com base nos resultados apurados na Tabela 1 é possível verificar que todos os modelos de regressão obtiveram significância ao nível de 5\%. Sendo que a regressão do ano de 2008 auferiu maior nível de significância. 
As correlações dos modelos foram elevadas para os anos de 2008 e 2009, o que demonstra uma alta relação entre as variáveis independentes e a variável dependente. Nos demais anos as correlações foram moderadas.

Os resultados das regressões permitiram calcular o índice de gerenciamento de resultado de empresas pertencentes aos Setores Regulados.

Para o cálculo das diferenças de média foi utilizado o método estatístico teste-T, que mostra as diferenças estatísticas no gerenciamento de resultados para o estudo em tela.

Desta forma, a Tabela 2 mostra se existe ou não diferença estatística no gerenciamento de resultados das empresas pertencentes aos setores regulados listadas na BM\&FBovespa.

Tabela 2: Diferença de médias para o gerenciamento.

\begin{tabular}{|c|c|c|c|c|c|c|c|c|}
\hline & & \multicolumn{2}{|c|}{$\begin{array}{l}\text { Levene's Test for } \\
\text { Equality of Variances }\end{array}$} & \multicolumn{5}{|c|}{ t-test for Equality of Means } \\
\hline & & $\mathrm{F}$ & Sig. & $\mathrm{t}$ & $\mathrm{df}$ & $\begin{array}{l}\text { Sig. }(2- \\
\text { tailed })\end{array}$ & $\begin{array}{l}\text { Diferença } \\
\text { Média }\end{array}$ & $\begin{array}{l}\text { Erro } \\
\text { Padrão }\end{array}$ \\
\hline \multirow[t]{2}{*}{ AD_2005 } & Com GC & 1,2011 & 0,2785 & 0,3551 & 49 & 0,7240 & 0,0107 & 0,0302 \\
\hline & Sem GC & & & 0,4196 & 34,3103 & 0,6774 & 0,0107 & 0,0256 \\
\hline \multirow[t]{2}{*}{ AD_2006 } & Com GC & 3,6842 & 0,0608 & 0,6781 & 49 & 0,5009 & 0,0300 & 0,0443 \\
\hline & Sem GC & & & 1,0280 & 46,5293 & 0,3093 & 0,0300 & 0,0292 \\
\hline \multirow[t]{2}{*}{ AD_2007 } & Com GC & 0,0010 & 0,9754 & 1,8607 & 49 & 0,0688 & 0,1584 & 0,0851 \\
\hline & Sem GC & & & 1,6783 & 19,5938 & 0,1092 & 0,1584 & 0,0944 \\
\hline \multirow[t]{2}{*}{ AD_2008 } & Com GC & 2,0006 & 0,1636 & 0,8323 & 49 & 0,4093 & 0,0488 & 0,0586 \\
\hline & Sem GC & & & 1,2029 & 48,9698 & 0,2348 & 0,0488 & 0,0406 \\
\hline \multirow[t]{2}{*}{ AD_2009 } & Com GC & 4,0872 & 0,0487 & 0,6098 & 49 & 0,5448 & 0,0114 & 0,0187 \\
\hline & Sem GC & & & 0,8413 & 47,8288 & 0,4044 & 0,0114 & 0,0136 \\
\hline
\end{tabular}

Fonte: Dados da Pesquisa

Os resultados descritos na Tabela 2 mostram que não existe diferença significativa entre o nível de gerenciamento de resultados de empresas de setores regulados com e sem governança corporativa. Esta consideração é possível devido ao fato de todos os índices de significância alcançar o valor maior do que o considerado por este estudo, de $5 \%$.

Neste contexto é possível descrever que não existe diferença estatisticamente comprovada entre o nível de gerenciamento de resultado de empresas dos setores regulados com governança corporativa e sem esta característica.

Por fim, os resultados da presente pesquisa, correspondem ao estudo de Silva, Galdi e Teixeira (2010), e igualmente encontrou evidências estatísticas de práticas de gerenciamento de resultados em empresas de capital aberto pertencentes a setores regulados.

\section{CONSIDERAÇÕES FINAIS}

Este estudo teve por objetivo investigar se as empresas listadas na BM\&FBovespa pertencentes a setores regulados efetuam gerenciamento de resultados contábeis, e identificar se a relação entre o índice de governança corporativa destas empresas influencia o gerenciamento de resultados das mesmas.

Mediante a análise da literatura abordada neste trabalho, observou-se que o GR pode ocorrer também nas empresas de setores regulados, contudo, as razões para tal não foram objeto da presente pesquisa. 
O fator regulamentação pública de setores da economia, que numa abordagem de senso comum, é visto como fator de prevenção ou atenuante do gerenciamento de resultado em empresas reguladas, cientificamente pode não ser preponderante, porém, para investigar tal hipótese recomenda-se a realização de pesquisas mais específicas.

Os resultados obtidos mostram existir gerenciamento de resultados nas companhias abertas de setores regulados. No entanto, não foram encontradas diferenças estatisticamente relevantes entre o nível de gerenciamento de resultado de empresas dos setores regulados com governança corporativa e empresas deste setor sem esta característica.

\section{REFERÊNCIAS}

BAPTISTA, Evelyn Maria Boya. É possível delinear um perfil das empresas brasileiras com maior propensão ao gerenciamento? In: CONGRESSO USP DE CONTROLADORIA E CONTABILIDADE, 8.; São Paulo. Anais ... São Paulo: USP. p. 1-16, 2008.

BARROSO, Luis Roberto. Constituição, Ordem Econômica e Agências Reguladoras. Revista Eletrônica de Direito Administrativo Econômico, Salvador, n. 1, fev./mar./abr. 2005.

BM\&FBOVESPA. Governança Corporativa. Disponível em: <www.bmfbovespa.com.br>. Acesso em: 07 jul. 2011.

BOWEN, Robert M.; RAJGOPAL, Shivaram; VENKATACHALAM, Mohan. Accounting Discretion, Corporate Governance and Firm Performance (January 2005). In: 14th Annual Conference on Financial Economics and Accounting (FEA); EFA 2003 Annual Conference. Paper n. 127. Disponível em: <http://ssrn.com/abstract=367940>. Acesso em: 06 jun. 2011.

BOWMAN, R.; NAVISSI, F. Earnings management and abnormal returns: Evidence from the 1970-1972 price control regulations. Accounting and Finance, v. 43, n. 1, p. 1-19, 2003.

BRASIL. Agências Reguladoras. Disponível em: <http://www.brasil.gov.br/sobre/obrasil/estrutura/agencias-reguladoras-fiscalizam-a-qualidade-dos-servicos $>$ Acesso em: 11 jun. 2011.

CAHAN, Steven F. The Effect of Antitrust Investigations on Discretionary Accruals: A Refined Test of Political-Cost Hypothesis. The Accounting Review, v. 67, n. 1, p. 77-95, Jan. 1992.

COSENZA, José Paulo; GRATERON, Ivan Ricardo Guevara. A Responsabilidade do Auditor Frente às Práticas de Contabilidade Criativa. Revista Paulista de Contabilidade, São Paulo, ed. 487 , p. 5-21, set. 2003.

CUPERTINO, Cesar Medeiros. Gerenciamento Fraudulento de Resultados Contábeis, o Caso do Banco Nacional. In: Encontro da EnANPAD, 28., 2004, Curitiba. Anais... Curitiba, 2004.

Earnings Management: Evidência Empírica. In: CONGRESSO USP DE

CONTROLADORIA E CONTABILIDADE, 4., 2004, São Paulo. Anais... São Paulo: USP, 2004. P. 1-16. 
DECHOW, Patricia M.; SKINNER, Douglas J. Earnings Management: Reconciling the Views of Accounting Academics, Practitioners, and Regulators. Accounting Horizons, v. 14, n. 2, 2000 .

FIANI, Ronaldo. Teoria da regulação econômica: estado atual e perspectivas futuras. Rio de Janeiro, Instituto de Economia - UFRJ, 1998. Texto para Discussão n. 423. Disponível em: $<$ http://www.ie.ufrj.br/grc/pdfs/teoria_da_regulacao_economica.pdf $>$. Acesso em: 06 jun. 2011.

GIL, Antonio Carlos. Como Elaborar Projetos de Pesquisa. 5. ed. São Paulo: Atlas, 2010.

GOULART, André Moura Cintra. Gerenciamento de Resultados Contábeis em Instituições Financeiras no Brasil. 2004. 211 f. Tese (Ciências Contábeis). Faculdade de Economia, Administração e Contabilidade da Universidade de São Paulo - USP, São Paulo. 2004.

GRUN, Roberto. Atores e Ações na Construção da Governança Corporativa Brasileira. Revista Brasileira de Ciências Sociais, São Paulo, v. 18, n. 52, jun. 2003.

HAN, Jerry C. Y.; WANG, Shiing-Wu. Political costs and earnings management of oil companies during the 1990 Persian Gulf crisis. The Accounting Review, v. 73, n. 1, p. 103117, jan. 1998.

HEALY, Paul. M.; WAHLEN, James Michael. A review of the earnings management literature and its implications for standard setting. Accounting Horizons, v. 13, n. 4, p. 365383, dec. 1999.

INSTITUTO BRASILEIRO DE GOVERNANÇA CORPORTATIVA. Origem da boa governança. Disponível em: <http://www.ibgc.org.br/Secao.aspx?CodSecao=18> Acesso em: 08 jul. 2011.

IUDÍCIBUS, Sérgio de; MARTINS, Eliseu; GELBCKE, Ernesto R. Manual de contabilidade das sociedades por ações. $5^{\text {a }}$. ed. São Paulo: Atlas, 2000.

JONES, Jennifer J. Earnings Management during import relief investigations. Journal of Accounting Research, v. 29, n. 2, p. 193-228, autumn, 1991.

KANG, Sok-Hyon. SIVARAMAKRISHNAN, K. Issues in Testing Earnings Management and an Instrumental Variables Approach. Journal of Accounting Research. v. 33, n. 2. Autumn. 1995.

LANZANA, Ana Paula. Relação entre Disclosure e Governança Corporativa das empresas brasileiras. 2004. 154 f. Dissertação (Mestrado em Administração) - Faculdade de Economia, Administração e Contabilidade, Universidade de São Paulo, São Paulo.

MALACRIDA, Mara Jane Contrera; YAMAMOTO, Marina Mitiyo. Governança Corporativa: Nível de Evidenciação das Informações e sua Relação com a Volatilidade das Ações do Ibovespa. Revista Contabilidade e Finanças, São Paulo, Edição Comemorativa, p. 65-79, set. 2006. 
MARTINEZ, Antonio Lopo. Gerenciamento dos resultados contábeis: estudo empírico das companhias abertas brasileiras. 2001. 153 f. Tese (Doutorado em Ciências Contábeis) Faculdade de Economia, Administração e Contabilidade, Universidade de São Paulo, São Paulo.

Antonio Lopo. Detectando Earnings Management no Brasil: Estimulando as Acumulações Discricionárias. In: Congresso USP, 4., 2004, São Paulo. Anais... São Paulo: USP, 2004. p. 15.

PEANO, Claudia De Rosa. Regulação Tarifária do Setor de Distribuição de Energia Elétrica no Brasil: Uma Análise da Metodologia de Revisão Tarifária Adotada pela ANEEL. 2005. 102 f. Dissertação (Mestrado em Energia) - Instituto de Eletrotécnica e Energia/Escola Politécnica/Faculdade de Economia e Administração, Universidade de São Paulo, São Paulo.

PIRES, José Claudio Linhares; Piccinini, Maurício Serrão. A Regulação dos Setores de InfraEstrutura no Brasil. In: GIAMBIAGI, F.; MOREIRA, M. M. (Orgs.). A economia brasileira nos anos 90. Rio de Janeiro: BNDES, 1999.

POSSAS, Mario Luiz; FAGUNDES, Jorge; PONDÉ, João Luiz. Defesa da concorrência e regulação de setores de infra-estrutura em transição. In: POSSAS, Mario Luiz. (Org.).

Ensaios sobre Economia e Direito da Concorrência. São Paulo: Singular, 2002.

RAMOS, Gizele Martins; MARTINEZ, Antonio Lopo. Governança Corporativa. Revista Contemporânea em Contabilidade. Florianópolis, v.1, n. 6, p. 143-164, 2006.

RICHARDSON, R. Pesquisa Social: métodos e técnicas. 2.ed. São Paulo: Atlas, 1989.

SÁ, Graciano. A Revolução Cultural no Mercado Acionário. RAUSP, São Paulo, v. 38, n. 2, p. 112-125, abr./mai./jun. 2003.

SALGADO, Lucia Helena; MOTTA, Ronaldo Seroa da. Marcos Regulatórios no Brasil: O que foi feito e o que falta fazer. Rio de Janeiro: IPEA, 2005.

SANCOVSCHI, Moacir; MATOS, Felipe Faissol Janot de. Gerenciamento de Resultados: Que Pensam Administradores, Contadores e Outros Profissionais de Empresas no Brasil. Revista de Administração Contemporânea, Curitiba, v.7, n. 4, p. 141-161, 2003.

SILVA, Maria Borba de; GRIGOLO, Tânia Maris. Metodologia da Pesquisa e Elaboração de Dissertação. 3. ed. Florianópolis: EDUFSC, 2001.

SILVA, Márcio de Souza e; GALDI, Fernando Caio; TEIXEIRA, Arilda M. C.. Estudo sobre o Efeito das Eleições Presidenciais no Gerenciamento de Resultados de Empresas Atuantes em Setores Regulados. Revista Contabilidade Vista e Revista, São Paulo, v. 21, n. 2, p. 4568, abr/jun. 2010.

SILVEIRA, Alexandre Di Miceli da. Governança Corporativa, Desempenho e Valor da Empresa no Brasil. 152 f. Dissertação (Mestrado em Administração) - Programa de PósGraduação em Administração, Universidade de São Paulo, São Paulo, 2002. 
TUKAMOTO, Yhurika Sandra; LOPES, Alexsandro Broedel. Contribuição ao Estudo do "Gerenciamento de Resultados": Uma Comparação entre as Companhias Abertas Brasileiras Emissoras de ADRs e não Emissoras de ADRs. RAUSP, São Paulo, v. 42, n.1, jan./mar. 2007. 